\title{
Effectiveness of sub-maximal intermittent exercise on muscle glycogen depletion, PGC-1 $\alpha$ and PDK-4 gene expression
}

\author{
Keisuke Shiose $^{1}$, Takuro Tobina ${ }^{2,3}$, Yasuki Higaki ${ }^{3,4}$, Akira Kiyonaga ${ }^{3,4}$, Hiroaki Tanaka ${ }^{3^{*}}$ \\ ${ }^{1}$ Graduate School of Sports and Health Science, Fukuoka University, Fukuoka, Japan \\ ${ }^{2}$ Faculty of Nursing and Nutrition, University of Nagasaki, Nagasaki, Japan \\ ${ }^{3}$ Fukuoka University Institute for Physical Activity, Fukuoka, Japan \\ ${ }^{4}$ Faculty of Sports and Health Science, Fukuoka University, Fukuoka, Japan \\ Email: ${ }^{*}$ htanaka@,fukuoka-u.ac.jp
}

Received 25 September 2012; revised 25 October 2012; accepted 7 November 2012

\begin{abstract}
Several metabolic gene expressions are regulated in concert with muscle glycogen status. We hypothesized that intermittent exercise performed at high but sub-maximal intensities with long recovery periods would induce a low glycogen state that would stimulate peroxisome proliferator-activated receptor- $\gamma$ coactivator-1 $\alpha$ (PGC1- $\alpha$ ) and pyruvate dehydrogenase kinase-4 (PDK-4) gene expression in muscle. Nine young human subjects performed two intermittent exercise sessions. One session consisted of $60 \mathrm{~s}$ cycling bouts at $\mathrm{VO}_{2} \mathrm{max}\left(\mathrm{IE}_{100 \%}\right)$, and the other session consisted of $75 \mathrm{~s}$ cycling bouts at $80 \% \quad \mathrm{VO}_{2} \mathrm{max}$ (IE $\left.{ }_{80 \%}\right)$. Twelve bouts of exercise were completed in both sessions with a $4 \mathrm{~min}$ rest between each bout. Muscle specimens were obtained at pre-exercise and immediately, $1.5 \mathrm{~h}$ and $3 \mathrm{~h}$ post-exercise. Muscle glycogen was significantly decreased after both sessions $\left(\mathrm{IE}_{100 \%}, 94.1 \pm 5.8\right.$ to $38.7 \pm 5.5 \mathrm{mmol} / \mathrm{kg} \mathrm{w.w.;} \mathrm{IE}_{80 \%}$, $94.6 \pm 9.1$ to $53.3 \pm 4.8 \mathrm{mmol} / \mathrm{kg}$ w.w.; both $P<0.05$ vs pre-exercise). Muscle glycogen depletion was greater in $\mathrm{IE}_{100 \%}$ than in $\mathrm{IE}_{\mathbf{8 0} \%}(P<\mathbf{0 . 0 5})$. PGC-1 $\alpha$ and PDK4 mRNA expression were significantly increased after exercise in both $\mathrm{IE}_{100 \%}$ and $\mathrm{IE}_{\mathbf{8 0} \%}$ (PGC-1 $\alpha$ : $\sim 3.7$ and 2.9-fold, respectively; PDK-4: $\sim 11.1$ and $\sim 3.5$-fold, respectively; all $P<0.05)$. Maximal PDK-4 mRNA expression after exercise was significantly greater in $\mathrm{IE}_{\mathbf{1 0 0 \%}}$ than in $\mathrm{IE}_{\mathbf{8 0} \%}(P<\mathbf{0 . 0 5})$. In conclusion, high but sub-maximal intermittent exercise decreased muscle glycogen and stimulated PGC-1a and PDK-4 mRNA expression, suggesting that increasing exercise intensity contributes to muscle glycogen depletion and PDK-4 mRNA expression in human skeletal muscle.
\end{abstract}

${ }^{*}$ Corresponding author.
Keywords: Intermittent Exercise; Muscle Glycogen;

Peroxisome Proliferator-Activated Receptor- $\gamma$

Coactivator- $1 \alpha$; Pyruvate Dehydrogenase Kinase- 4

\section{INTRODUCTION}

Exercise training-induced increase in mitochondrial function and fat-oxidative capacity are result from the cumulative effects of transient increases in mRNA expression after successive exercise sessions [1]. A key genes of mitochondrial function and fat-oxidative capacity are peroxisome proliferator-activated receptor- $\gamma$ coactivator$1 \alpha$ (PGC-1 $\alpha)$ and pyruvate dehydrogenase kinase-4 (PDK-4). PGC-1 $\alpha$ expression was reported to be increased by an acute bout of exercise [2,3], and promoted expression of several mitochondria biogenesis-related genes (e.g. nuclear respiratory factors, transcription factor A) [4-6]. PDK-4 is highly expressed in skeletal muscle [7]. PDK-4 inactivates pyruvate dehydrogenase (PDH) by phosphorylating the E1 subunit. Inactivation of $\mathrm{PDH}$ impairs the conversion of pyruvate to acetyl-CoA, consequently switching the energy substrate from glucose to lipid [8]. PGC-1 $\alpha$ and PDK-4 expression may be regulated in concert with muscle glycogen status. It was suggested that 5'AMP-activated protein kinase (AMPK), one of regulator of exercise induced PGC- $1 \alpha$ expression, contains a glycogen binding domain [9-11], and phosphorylated levels of AMPK are increased with decreasing muscle glycogen [12-14]. PDK-4 transcriptional activation was also shown to be enhanced by a low muscle glycogen state via change in intracellular distribution of glycogen regulatory enzymes such as protein phosphatase 1 and glycogen synthase kinase 3 [15].

It was previously reported that the efficiency of muscle glycogen decreases with increasing exercise intensity [16]. However, high-intensity exercise is difficult to perform continuously, and the rate of glycogen oxidation 
decreases with exercise duration [17]. Therefore, shortterm high-intensity Intermittent Exercise (IE) might be useful for decreasing muscle glycogen. McCartney et al. examined the metabolic change during four bouts of $30 \mathrm{~s}$ of "all out" exercise, and reported that muscle glycogen decreased dramatically after the first and second exercise bouts, while glycogenolysis was inhibited during the third and fourth exercise bouts [18]. An inhibition of glycogenolysis enzyme (phosphofructokinase and phosphorylase) activity by the decrease in muscle $\mathrm{pH}$ may explain the inhibition of glycogenolysis by intense exercise $[19,20]$. Restoration of muscle $\mathrm{pH}$ is known to occur progressively after exercise [21]. We previously studied the effects of consecutive maximal exercise with a long-term recovery period on muscle glycogen metabolism, and suggesting that a sufficient recovery between intense exercise has a favorable effect on muscle glycogen decrease [22]. Nevertheless, a limitation of maximal IE is that it is extremely strenuous and difficult to complete. Recently, Little et al. proposed a practical model of IE that consists of $8-12$ one-minute bouts at $\sim 100 \%$ of peak power output separated by a 75 s recovery [23]. In that study, IE stimulated mitochondrial biogenesis-related gene expression. However, the levels of muscle glycogen levels with exercise were not reported.

In the present study, we hypothesized that high but sub-maximal IE with a long recovery period between exercise bouts would result in decreased muscle glycogen and stimulation of PGC- $1 \alpha$ and PDK- 4 expression without a heavy physical demand. To examine this hypothesis, we compared the effects of two different IE intensities $\left(80 \%\right.$ and $\left.100 \% \mathrm{VO}_{2} \max \right)$ with a 4 min recovery period on physiological responses, muscle glycogen levels, and PGC- $1 \alpha$ and PDK-4 gene expression.

\section{MATERIAL AND METHODS}

\subsection{Subjects}

Nine healthy men participated in this study $(22 \pm 1$ year, $173.2 \pm 3.4 \mathrm{~cm}, 64.1 \pm 4.4 \mathrm{~kg}$ ). No subjects were specifically engaged in training. The subjects were fully informed of any risks and discomfort associated with the IE sessions and muscle biopsy procedures before giving their consent to participate. The study procedure was approved by the ethical committee of Fukuoka University.

\subsection{Measurement of $\mathrm{VO}_{2} \mathrm{max}$}

Before the first session, subjects made several familiarization visits to the laboratory to become oriented with the study procedures. During one of these visits, subjects performed an incremental test to exhaustion on an electronically braked cycle ergometer (Rechor; Lode,
Groningen, The Netherlands) to determine $\mathrm{VO}_{2} \max$ using an on-line gas collection system (ARCO 2000; ARCO System, Chiba, Japan). The value used for $\mathrm{VO}_{2}$ max corresponded with the highest value achieved over a $30 \mathrm{~s}$ collection period. All subjects fulfilled at least one of the two following $\mathrm{VO}_{2}$ max criteria [24,25].

1) A plateau in $\mathrm{VO}_{2}$ where the increase in $\mathrm{VO}_{2}$ was less than $<150 \mathrm{ml} / \mathrm{min}$ with increasing workload.

2) Peak blood lactate concentration $\geq 8 \mathrm{mmol} / \mathrm{L}$.

\subsection{High-Intensity Intermittent Exercise}

All subjects participated in two high-intensity IE sessions conducted in random order at least 5 days apart. One of the IE sessions consisted of $60 \mathrm{~s}$ cycling bouts at $\mathrm{VO}_{2} \mathrm{max}$ $\left(\mathrm{IE}_{100 \%}\right)$, and the other session consisted of $75 \mathrm{~s}$ cycling bouts at $80 \% \mathrm{VO}_{2} \max \left(\mathrm{IE}_{80 \%}\right)$. In both sessions, 12 bouts of exercise were completed with a 4 min rest between each bout, and the total work performed in each bout was the same. The subjects were instructed to maintain their normal diet throughout the duration of the research and to refrain from alcohol consumption and strenuous exercise for $24 \mathrm{~h}$ prior to each session (Figure 1).

On the day of each exercise session, the subjects arrived at the laboratory between 6:30 am - 9:30 am after an overnight fast. A catheter was inserted into the antecubital vein, and a resting blood sample was taken at least $15 \mathrm{~min}$ after the catheter insertion to minimize stress reactions. Thereafter, resting muscle biopsies were obtained using the fine-needle biopsy procedure. After a light stretch, each subject performed the IE protocol at a stable speed of approximately $60 \mathrm{rpm}$. Each subject was allowed water, but no food, pre- and post-exercise.

During exercise, HR was collected every millisecond using an electrocardiogram system (CARDIMAX FX3301; Fukuda Denshi Co., Tokyo, Japan). Outputs from the electrocardiogram were collected on a personal

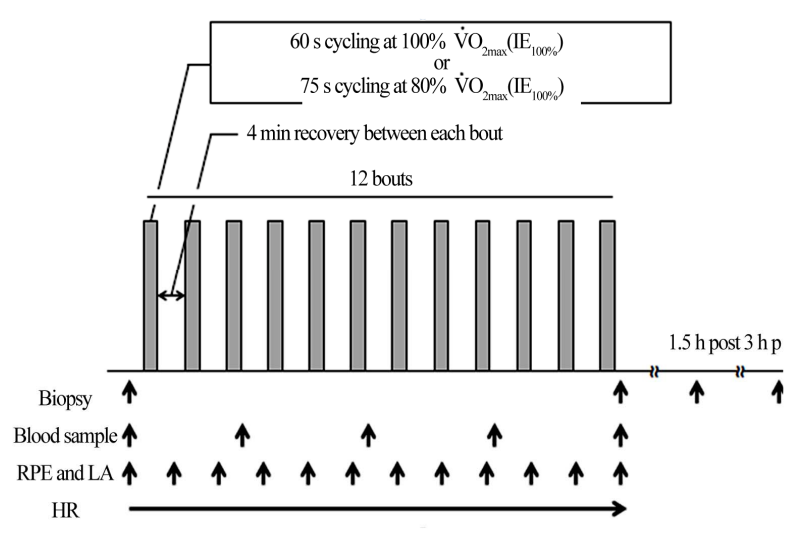

Figure 1. Experimental sessions. Subjects performed two intermittent exercise sessions. One session consisted of $60 \mathrm{~s}$ cycling bouts at $\mathrm{VO}_{2} \max \left(\mathrm{IE}_{100 \%}\right)$, and the other session consisted of $75 \mathrm{~s}$ cycling bouts at $80 \% \mathrm{VO}_{2} \max \left(\mathrm{IE}_{80 \%}\right)$ 
computer using waveform processing software (Chart 5; AD Instruments Japan Inc., Nagoya, Japan) via an AD conversion board (PowerLab 8 sp; AD Instruments, Japan Inc.). All HR data were averaged every $1 \mathrm{~s}$. Immediately after each exercise bout, ratings of perceived exertion (RPE) were obtained. To determine blood lactate concentration, $20 \mu \mathrm{L}$ of blood was collected from the ear lobe. Blood samples were drawn from the antecubital vein after every three bouts. Further muscle biopsies were taken immediately, $1.5 \mathrm{~h}$ and $3 \mathrm{~h}$ post-completion of each session.

\subsection{Blood Analysis}

Blood samples were centrifuged at $3000 \times \mathrm{g}$ at $4^{\circ} \mathrm{C}$ for 15 min. Plasma and serum were stored at $-30^{\circ} \mathrm{C}$ for later analysis. Blood analysis included glucose (Hexokinase ultraviolet assay kit; Shino-Test, Tokyo, Japan), insulin (Chemiluminescent enzyme immunoassay kit; Fujirebio, Tokyo, Japan), triglyceride (Enzymatic kit; Sekisui Medical, Tokyo, Japan), free fatty acids (Enzymatic kit; Eiken Chemical, Tokyo, Japan), and catecholamine (High performance liquid chromatography method). All blood analyses were conducted by an independent company (SRL Inc., Tokyo, Japan)

\subsection{Muscle Biopsy Procedures}

Muscle samples were taken using a previously described method [26]. Muscle biopsy tissue specimens (approximately $10 \mathrm{mg}$ ) were obtained from middle of the vastus lateralis of the dominant leg using a Bard MAGNUM biopsy instrument (C. R. Bard; Covington, GA, USA) with a $16 \mathrm{~g}$ disposable needle. Lidocaine tape agent (Penles; Nitto Denko Corp., Tokyo, Japan) was applied to the biopsy site at $>2 \mathrm{~h}$ before biopsy. To facilitate the insertion of the biopsy needle, a hole was opened in the skin with an $18 \mathrm{~g}$ injection needle immediately before the biopsy. After insertion, the trigger was pushed with the fine needle perpendicular to the hole of the skin. Blood was removed immediately from the biopsy tissue specimen using gauze, and was frozen with liquid nitrogen and stored at $-80^{\circ} \mathrm{C}$ until analysis.

\subsection{Gene Expression Analysis}

Total RNA was extracted from approximately $5 \mathrm{mg}$ of freeze-dried muscle. All samples were homogenized using a POLYTRON homogenizer. mRNA was extracted using the Maxwell ${ }^{\circledR} 16$ LEV System (Promega, Tokyo, Japan). Real-time PCR (Light Cycler; Roche Diagnostics, Tokyo, Japan) was used for qualitative analysis of gene expression. The specific genes analyzed and the primers used are presented in Table 1. Real-time PCR was performed with a SYBR Green I (Light Cycler Fast Start DNA Master SYBR Green I; Roche Diagnostics) reagent.

The specificity of the PCR product was identified using a melting curve analysis that determined the temperature of denaturation of the PCR product through a heating procedure. The melting curve patterns were compareed by visual inspection. 36B4 was used as a housekeeping gene to normalize target mRNA. The average CT values of the unknown samples were converted to relative expression data using an appropriate standard curve.

\subsection{Muscle Glycogen Measurement}

Muscle glycogen content was determined using previously reported procedures [27]. Muscle (2 - $5 \mathrm{mg}$ ) was dissolved in $30 \% \mathrm{KOH}$ and $5 \% \mathrm{Na}_{2} \mathrm{SO}_{4}$ at $70^{\circ} \mathrm{C}$ for 15 min. Glycogen was then precipitated by mixing with an absolute alcohol, and was stored at $-20^{\circ} \mathrm{C}$ overnight. The precipitates were collected by centrifugation at 13,000 $\times$ $\mathrm{g}$ for $5 \mathrm{~min}$. Glycogen was hydrolyzed in $6 \mathrm{~N} \mathrm{H}_{2} \mathrm{SO}_{4}$ at $100^{\circ} \mathrm{C}$ for $45 \mathrm{~min}$ and cooled. Samples were neutralized with $1 \mathrm{~N} \mathrm{NaOH}$, and glucose was measured using the glucose (HK) reagent (Sigma, Saint Louis, MO, USA). The intra-assay coefficient of variation $(\mathrm{CV})$ was $6.9 \%$ $7.2 \%$.

\subsection{Statistical Analysis}

All data are expressed as mean \pm SEM. PDK-4 and PGC- $1 \alpha$ mRNA abundance were normalized to $36 \mathrm{~B} 4$ mRNA abundance, and post-exercise sample data were expressed relative to the corresponding pre sample that was set to one. Two-way ANOVAs with repeated measures were used to evaluate the interaction of time and condition in $\mathrm{IE}_{100 \%}$ and $\mathrm{IE}_{80 \%}$, followed by TukeyKramer's post-hoc test and Student's paired t-test to locate the differences when significant main effects were

Table 1. Real-time PCR primer sequences and Gene Bank Accession numbers.

\begin{tabular}{cccc}
\hline Gene & $\begin{array}{c}\text { Gene bank } \\
\text { accession number }\end{array}$ & Forward primer (5' - 3’) & Reverse primer (5’ - 3’) \\
\hline PGC-1 $\alpha$ & AF106698 & ACCGTTATACCTGTGATGC & CCAGAGAGTCATACTTGCTC \\
PDK-4 & NM_002612 & GCCCGTCCCCGCTGTCC & TCTGGTCATCTGGGCTTTTCTCAT \\
36 B4 & M17885 & AGGTGTTCGACAATGGCAGCATCTAC & TCGTTTGTACCCGTTGATGATAGA \\
\hline
\end{tabular}


found. Differences were considered significant at $P<$ 0.05. Statistical calculations were performed using PASW Statistic 18 (SPSS Inc., Chicago, IL, USA).

\section{RESULTS}

\subsection{Physiological Responses and Blood Metabolism}

HR, RPE, and blood lactate concentration during exercise are shown in Table 2. Exercise-induced increases in HR and RPE demonstrated a significant main effect for exercise session protocol, with no significant interactions. The exercise-induced increase in blood lactate concentration was significantly greater in $\mathrm{IE}_{100 \%}$ compared with $\mathrm{IE}_{80 \%}(P<0.05)$. $\mathrm{IE}_{100 \%}$ and $\mathrm{IE}_{80 \%}$ increased blood triglyceride, adrenaline, and noradrenaline, and decreased blood Free Fatty Acids (FFA) concentration (main effect for time, $P<0.01)$. For all blood biochemistry measurements, there were no significant interactions (Table 3).

\subsection{Muscle Glycogen}

At rest, muscle glycogen contents were similar between $\mathrm{IE}_{100 \%}$ and $\mathrm{IE}_{80 \%}$, and were decreased significantly after exercise in both sessions ( $\mathrm{IE}_{100 \%}, 94.1 \pm 5.8$ to $38.7 \pm 5.5$ $\mathrm{mmol} / \mathrm{kg}$ w.w; $\mathrm{IE}_{80 \%}, 94.6 \pm 9.1$ to $53.3 \pm 4.8 \mathrm{mmol} / \mathrm{kg}$ w.w; $P<0.05$ vs pre-exercise for both). The rate of muscle glycogen depletion was significantly greater in $\mathrm{IE}_{100 \%}$ compared with $\mathrm{IE}_{80 \%}(58.5 \pm 5.3 \%$ vs $43.1 \pm 2.7 \% ; P<$ $0.05)$.

\subsection{Expression of PGC-1 $\alpha$ and PDK-4 Genes}

The $\mathrm{IE}_{100 \%}$ and $\mathrm{IE}_{80 \%}$ significantly increased PGC- $1 \alpha$ mRNA abundance $\sim 3$.7-fold and $\sim 2$.9-fold, respectively, throughout the $3 \mathrm{~h}$ recovery period (main effect for time,

Table 2. HR, RPE, and blood lactate concentrations during exercise.



Values are mean \pm SEM $(n=9)$. ${ }^{\dagger}$ Significant main effect for time. ${ }^{\#}$ Significant main effect for condition. ${ }^{\$}$ Significant interaction between time and condition. * Significant difference compared to rest value in same experimental protocol.

Table 3. Blood glucose, insulin, FFA, triglyceride, adrenaline, and noradrenaline concentrations during exercise.

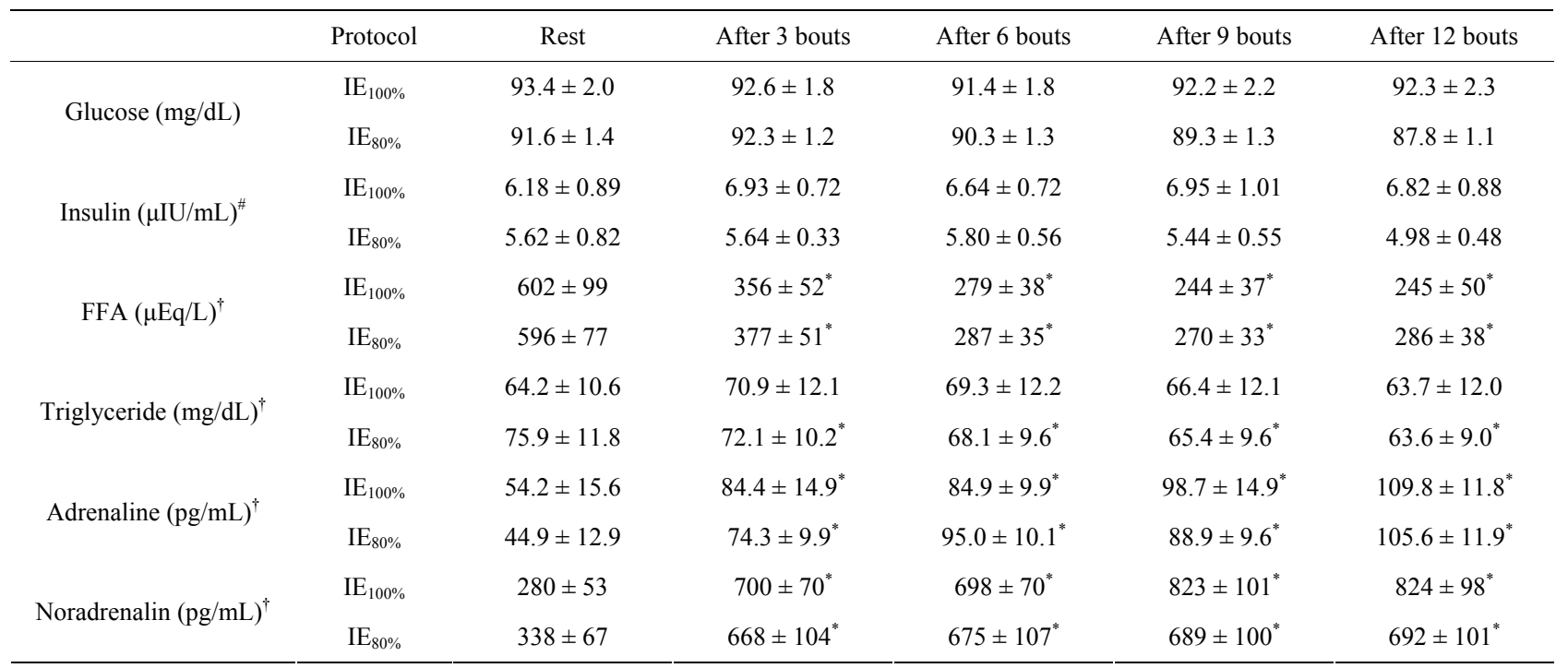

Values are mean \pm SEM $(n=9)$. 'Significant main effect for time. ${ }^{*}$ Significant main effect for condition. ${ }^{*}$ Significant difference compared with rest value in same experimental protocol. 
$P<0.05$ ), with no significant interaction. Further, $\mathrm{IE}_{100 \%}$ and $\mathrm{IE}_{80 \%}$ significantly increased PDK-4 mRNA abundance $\sim 11$.1-fold and $\sim 3.5$-fold, respectively, throughout the $3 \mathrm{~h}$ recovery period (main effect for time, $P<0.05$ ), with no significant interaction between session and time. Maximal PDK-4 mRNA abundance throughout the $3 \mathrm{~h}$ recovery period was significantly greater in $\mathrm{IE}_{100 \%}$ compared with $\mathrm{IE}_{80 \%}(P<0.05$; Figure 2).

\section{DISCUSSION}

The main findings of this study were that $\mathrm{IE}_{100 \%}$ and $\mathrm{IE}_{80 \%}$ sessions decreased muscle glycogen content and stimulated PGC- $1 \alpha$ and PDK-4 gene expression. In addition, increasing exercise intensity contributed to a greater depletion of muscle glycogen and PDK-4 expression. The decrease in muscle glycogen in the $\mathrm{IE}_{100 \%}$ was $15 \%$ greater than the decrease in response to $\mathrm{IE}_{80 \%}$, suggesting that the muscle glycogen decrease per amount of work



(a)

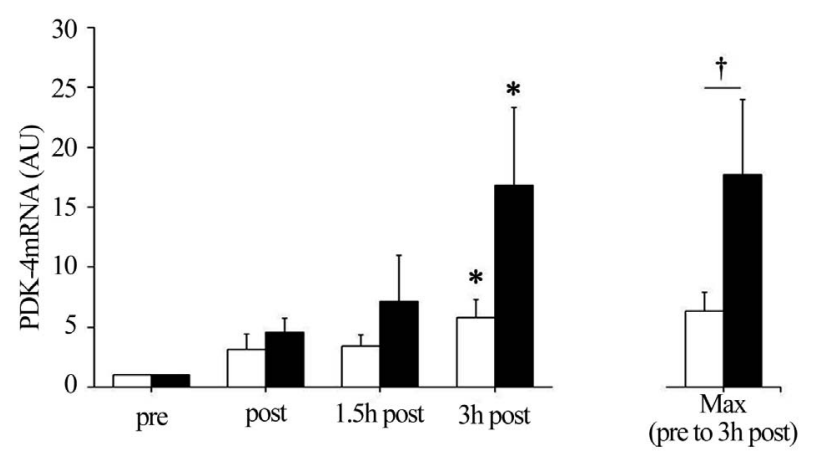

(b)

Figure 2. (a) Peroxisome proliferator-activated receptor gamma coactivator 1- $\alpha$ (PGC-1 $\alpha$ ) and (b) Pyruvate dehydrogenase kinase 4 (PDK-4) mRNA abundance. Summary data (mean \pm SEM) from the $\mathrm{IE}_{80 \%}(\square)$ and $\mathrm{IE}_{100 \%}$ ( $)$ showing fold change in mRNA abundance. Total RNA was isolated from muscle biopsies pre-exercise (pre) and immediately, $1.5 \mathrm{~h}$, and $3 \mathrm{~h}$ postexercise (post, $1.5 \mathrm{~h}$ post, and $3 \mathrm{~h}$ post, respectively). Significant $(P<0.05)$ main effects for time were found. ${ }^{*}$ Significantly $(P<0.05)$ different from pre in the same exercise session. ${ }^{\dagger}$ Significantly $(P<0.05)$ different between exercise sessions. was greater for $\mathrm{IE}_{100 \%}$ than $\mathrm{IE}_{80 \%}$. These data are supported by a previous study showing that the efficiency of the decrease in muscle glycogen is enhanced with increasing exercise intensity [16]. Considering the change of muscle glycogen content in the present study, it is possible that the decrease in muscle $\mathrm{pH}$ during $\mathrm{IE}_{100 \%}$ and $\mathrm{IE}_{80 \%}$ was not enough to inhibit glycogenolysis. Unfortunately, we did not measure muscle $\mathrm{pH}$ in the present study, while blood lactate concentrations during $\mathrm{IE}_{100 \%}$ and $\mathrm{IE}_{80 \%}$ were nearly $7 \mathrm{mmol} / \mathrm{L}$ and $4 \mathrm{mmol} / \mathrm{L}$, respectively. These values were less than half of the blood lactate concentration reported in a previous study demonstrating glycogenolysis inhibition during IE [18]. Thus, the 4 min rest period during sub-maximal IE may have been sufficient to promote a decrease in glycogen.

Similar to previous reports [28,29], we found that PGC- $1 \alpha$ and PDK-4 mRNA were significantly increased in the $3 \mathrm{~h}$ post-exercise in $\mathrm{IE}_{100 \%}$ and $\mathrm{IE}_{80 \%}$. PGC- $1 \alpha$ expression is mainly regulated by AMPK $[9,10]$, p38 mitogen-activated protein kinase [30], $\mathrm{Ca}^{2+}$-calmodulin dependent kinase II [31], and catecholamine stimulation [32]. Unfortunately, we were unable to measure these kinases, although it was reported that muscle glycogen availability relates negatively to AMPK activity [12-14]. Therefore, we speculate that the increase in AMPK activity related to the decrease in muscle glycogen and blood catecholamine concentrations may have stimulated PGC- $1 \alpha$ mRNA expression in $\mathrm{IE}_{100 \%}$ and $\mathrm{IE}_{80 \%}$. On the other hand, we found no relationship between muscle glycogen content and PGC- $1 \alpha$ mRNA expression. Mathai et al. previously reported a strong association between changes in muscle glycogen content and PGC$1 \alpha$ protein content in a wide range of conditions, including muscle glycogen depleted and supercompensated state [33]. However, this relationship seems weak when examining only the glycogen depleted state. Therefore, the difference between the sessions in terms of muscle glycogen depletion is insufficient to explain the relationship between muscle glycogen content and PGC- $1 \alpha$ expression. In accordance with previous findings showing that PDK-4 gene expression is stimulated in a low muscle glycogen state $[15,34]$, we found that muscle glycogen content was approximately $20 \%$ lower and the maximum value of PDK-4 mRNA throughout the $3 \mathrm{~h}$ recovery was 3.1-fold higher after $\mathrm{IE}_{100 \%}$ compared with $\mathrm{IE}_{80 \%}$. Therefore, we speculate that the low muscle glycogen state after $\mathrm{IE}_{100 \%}$ and $\mathrm{IE}_{80 \%}$ contributed to the increased in PDK-4 mRNA expression with decreasing muscle glycogen levels. Elevated blood FFA and reduced blood insulin were also reported to contribute to PDK-4 gene expression [34,35]. However, we found that blood FFA concentration decreased, while blood insulin concentration was not changed, during both sessions, suggesting that changes in these blood metabolites and 
hormones were not associated with PDK-4 mRNA expression. Spriet et al. reported that PDK-4 mRNA expression after both sessions was increased with advancing fasting duration [36]. In the present study, all subjects started exercise in a $10 \mathrm{~h}$ fasted state and were not allowed water until $3 \mathrm{~h}$ post exercise. Therefore, it is possible that exercise-induced PDK-4 expression after both sessions may be affected by the fasting state. The PGC- $1 \alpha$ and PDK-4 results in the present study are partly supported by findings of Cluberton et al. where glucose ingestion before exercise attenuated the exerciseinduced increase in PDK-4 mRNA expression, whereas the exercise-induced increase in PGC- $1 \alpha$ mRNA expression was not affected by the change in glucoseavailability [37]. Based on these results, we speculate that PDK-4 expression has a strong negative relationship with carbohydrate (blood glucose and muscle glycogen), whereas PGC- $1 \alpha$ expression has a weak negative relationship with carbohydrate.

In the present study, importantly, we also determined the physical demands of the IE protocols that use a long recovery period. In $\mathrm{IE}_{100 \%}$ and $\mathrm{IE}_{80 \%}$, the peak HR during exercise corresponded to $79.5 \%$ and $71.3 \%$ of HR reserve, respectively, which were relatively low compared with the value permitted by the American College of Sports Medicine's Exercise Guidelines for health in healthy people [23]. In addition, the RPE during the exercise session did not increase to extremely high levels (e.g. $\mathrm{IE}_{100 \%}, 12$ - 16; $\mathrm{IE}_{80 \%}, 11$ - 14). The $\mathrm{IE}_{100 \%}$ and $\mathrm{IE}_{80 \%}$ consisted of a combination of $\sim 75 \mathrm{~s}$ exercise bouts each separated by a $4 \mathrm{~min}$ recovery. These data suggest that this exercise pattern is tolerable and does not place strenuous physical demands on individuals. In addition to these results, a recent report indicated that PGC- $1 \alpha$ can coactivate genes associated with muscle plasticity and mitochondrial biogenesis as well as the suppression of inflammation [38]. Therefore, $\mathrm{IE}_{100 \%}$ and $\mathrm{IE}_{80 \%}$ have the potential to be effective exercise methods for both athletes and non-athletes.

\section{CONCLUSION}

We found that IE protocols with 4 min recovery periods between each 1 min exercise bout $\left(\mathrm{IE}_{100 \%}\right.$ and $\left.\mathrm{IE}_{80 \%}\right)$ markedly decreased muscle glycogen content and increased PGC- $1 \alpha$ and PDK-4 mRNA expression. In addition, increasing exercise intensity of IE elevated muscle glycogen depletion and PDK-4 expression.

\section{ACKNOWLEDGEMENTS}

This study was performed with the support of the Fukuoka University Institute for Physical Activity, a Technology Scientific Research Budget Basic Research Grant (A19200049 Strategic Research Infrastructure) from the Japanese Government's Ministry of Education, Culture,
Sports, Science and Technology (MEXT), and MEXT-Supported Program for Strategic Research Foundation at Private Universities, 20082012. We would like to thank all subjects for their time and effort in this study.

\section{REFERENCES}

[1] Perry, C.G., Lally, J., Holloway, G.P., Heigenhauser, G.J., Bonen, A. and Spriet, L.L. (2010) Repeated transient mRNA bursts precede increases in transcriptional and mitochondrial proteins during training in human skeletal muscle. The Journal of Physiology, 588, 4795-4810. doi:10.1113/jphysiol.2010.199448

[2] Terada, S., Goto, M., Kato, M., Kawanaka, K., Shimokawa, T. and Tabata, I. (2002) Effects of low-intensity prolonged exercise on PGC-1 mRNA expression in rat epitrochlearis muscle. Biochemical and Biophysical Research Communications, 296, 350-354. doi:10.1016/S0006-291X(02)00881-1

[3] Pilegaard, H., Saltin, B. and Neufer, P.D. (2003) Exercise induces transient transcriptional activation of the PGC1alpha gene in human skeletal muscle. The Journal of Physiology, 546, 851-858. doi:10.1113/jphysiol.2002.034850

[4] Puigserver, P., Wu, Z., Park, C.W, Graves, R., Wright, M. and Spiegelman, B.M. (1998) A cold-inducible coactivator of nuclear receptors linked to adaptive thermogenesis. Cell, 92, 829-839. doi:10.1016/S0092-8674(00)81410-5

[5] Wu, Z., Puigserver, P., Andersson, U., Zhang, C., Adelmant, G., Mootha, V., Troy, A., Cinti, S., Lowell, B., Scarpulla, R.C. and Spiegelman, B.M. (1999) Mechanisms controlling mitochondrial biogenesis and respiration through the thermogenic coactivator PGC-1. Cell, 98, 115124. doi:10.1016/S0092-8674(00)80611-X

[6] Wende, A.R., Schaeffer, P.J., Parker, G.J., Zechner, C., Han, D.H., Chen, M.M., Hancock, C.R., Lehman, J.J., Huss, J.M., McClain, D.A., Holloszy, J.O. and Kelly, D.P. (2007) A role for the transcriptional coactivator PGClalpha in muscle refueling. The Journal of Biological Chemistry, 282, 36642-36651. doi:10.1074/jbc.M707006200

[7] Bowker-Kinley, M.M., Davis, W.I., Wu, P., Harris, R.A. and Popov, K.M. (1998) Evidence for existence of tissue-specific regulation of the mammalian pyruvate dehydrogenase complex. Biochemical Journal, 329, 191196.

[8] Sugden, M.C. and Holness, M.J. (2003) Recent advances in mechanisms regulating glucose oxidation at the level of the pyruvate dehydrogenase complex by PDKs. American Journal of Physiology-Endocrinology and Metabolism, 284, E855-E862.

[9] Irrcher, I., Adhihetty, P.J., Sheehan, T., Joseph, A.M. and Hood, D.A. (2003) PPARgamma coactivator-1alpha expression during thyroid hormone and contractile activityinduced mitochondrial adaptations. American Journal of Physiology-Cell Physiology, 284, C1669-C1677.

[10] Irrcher, I., Ljubicic, V., Kirwan, A.F. and Hood, D.A. 
(2008) AMP-activated protein kinase-regulated activation of the PGC-1alpha promoter in skeletal muscle cells. PLoS One, 3, e3614. doi:10.1371/journal.pone.0003614

[11] Polekhina, G., Gupta, A., Van Denderen, B.J., Feil, S.C., Kemp, B.E., Stapleton, D. and Parker, M.W. (2005) Structural basis for glycogen recognition by AMP-activated protein kinase. Structure, 13, 1453-1462. doi:10.1016/j.str.2005.07.008

[12] Wojtaszewski, J.F., Jørgensen, S.B., Hellsten, Y., Hardie, D.G. and Richter, E.A. (2002) Glycogen-dependent effects of 5-aminoimidazole-4-carboxamide (AICA)-riboside on AMP-activated protein kinase and glycogen synthase activities in rat skeletal muscle. Diabetes, 51, 284-292. doi:10.2337/diabetes.51.2.284

[13] Wojtaszewski, J.F., MacDonald, C., Nielsen, J.N, Hellsten, Y., Hardie, D.G., Kemp, B.E., Kiens, B. and Richter, E.A. (2003) Regulation of 5'AMP-activated protein kinase activity and substrate utilization in exercising human skeletal muscle. American Journal of PhysiologyEndocrinology and Metabolism, 284, E813-E822.

[14] McBride, A. and Hardie, D.G. (2009) AMP-activated protein kinase-A sensor of glycogen as well as AMP and ATP. Acta physiologica (Oxford, England), 196, 99113. doi:10.1111/j.1748-1716.2009.01975.x

[15] Pilegaard, H., Keller, C., Steensberg, A., Helge, J., Pedersen, B.K., Saltin, B. and Neufer, P.D. (2002) Influence of pre-exercise muscle glycogen content on exercise-induced transcriptional regulation of metabolic genes. The Journal of Physiology, 541, 261-271.

doi:10.1113/jphysiol.2002.016832

[16] Gollnick, P.D., Piehl, K. and Saltin, B. (1974) Selective glycogen depletion pattern in human muscle fibres after exercise of varying intensity and at varying pedalling rates. The Journal of Physiology, 241, 45-57.

[17] Romijn, J.A., Coyle, E.F., Sidossis, L.S., Gastaldelli, A., Horowitz, J.F., Endert, E. and Wolfe, R.R. (1993) Regulation of endogenous fat and carbohydrate metabolism in relation to exercise intensity and duration. American Journal of Physiology, 265, E380-E391.

[18] McCartney, N., Spriet, L.L., Heigenhauser, G.F., Kowalchuk, J.M., Sutton, J.R. and Jones, N.L. (1986) Muscle power and metabolism in maximal intermittent exercise. Journal of Applied Physiology, 60, 1164-1169.

[19] Newsholme, E.A. and Start, C. (1972) Regulation in Metabolism. Wiley Interscience, New York.

[20] Chasiotis, D., Hultman, E. and Sahlin, K. (1983) Acidotic depression of cyclic AMP accumulation and phosphorylase $\mathrm{b}$ to a transformation in skeletal muscle of man. Journal of Applied Physiology, 335, 197-204.

[21] Sairyo, K., Ikata, T., Takai, H. and Iwanaga, K. (1993) Effect of active recovery on intracellular $\mathrm{pH}$ following muscle contraction, a 31P-MRS study. The Annals of Physiological Anthropology, 12, 173-179. doi:10.2114/ahs1983.12.173

[22] Shiose, K., Tobina, T., Higaki, Y., Kiyonaga, A. and Tanaka, H. (2011) An effective high-intensity intermittent exercise protocol for decreasing skeletal muscle glycogen. Japanese Journal of Physical Fitness and Sports Medicine, 60, 493-502. doi:10.7600/jspfsm.60.493
[23] Little, J.P., Safdar, A., Wilkin, G.P., Tarnopolsky, M.A. and Gibala, M.J. (2010) A practical model of low-volume high-intensity interval training induces mitochondrial biogenesis in human skeletal muscle: Potential mechanisms. Journal of Physiology, 588, 1011-1022. doi:10.1113/jphysiol.2009.181743

[24] Astrand, P.O. and Rodahl, K. (1986) Textbook of work physiology: Physiological bases of exercise. 3rd Edition, McGraw-Hill, New York. doi:10.2310/6640.2004.00030

[25] Whaley, M.H., Brubaker, P.H. and Otto, R.M., et al. (2006) ACSM's guidelines for exercise testing and prescription. 7th Edition, Lippincott Williams \& Wilkins, Baltimore.

[26] Tobina, T., Nakashima, H., Mori, S., Abe, M., Kumahara, H., Yoshimura, E., Nishida, Y., Kiyonaga, A., Shono, N. and Tanaka, H. (2009) The utilization of a biopsy needle to obtain small muscle tissue specimens to analyze the gene and protein expression. Journal of Surgical Research, 154, 252-257. doi:10.1016/j.jss.2008.07.011

[27] Higaki, Y., Wojtaszewski, J.F., Hirshman, M.F., Withers, D., Towery, H., White, M.F. and Goodyear, L.J. (1999) Insulin receptor substrate-2 is not necessary for insulin and exercise-stimulated glucose transport in skeletal muscle. The Journal of Biological Chemistry, 274, 2079120795. doi:10.1074/jbc.274.30.20791

[28] Wang, L., Psilander, N., Tonkonogi, M., Ding, S. and Sahlin, K. (2009) Similar expression of oxidative genes after interval and continuous exercise. Medicine \& Science in Sports \& Exercise, 41, 2136-2144. doi:10.1249/MSS.0b013e3181abclec

[29] Wang, L. and Sahlin, K. (2012) The effect of continuous and interval exercise on PGC- $1 \alpha$ and PDK4 mRNA in type I and type II fibres of human skeletal muscle. Acta physiologica (Oxford, England), 204, 525-532. doi:10.1111/j.1748-1716.2011.02354.x

[30] Akimoto, T., Pohnert, S., Li, P., Zhang, M., Gumbs, C., Rosenberg, P.B., Williams, R.S. and Yan, Z. (2005) Exercise stimulates Pgc-1alpha transcription in skeletal muscle through activation of the p38 MAPK pathway. The Journal of Biological Chemistry, 280, 19587-19593. doi:10.1074/jbc.M408862200

[31] Ojuka, E.O, Jones, T.E., Han, D., Chen, M. and Holloszy, J.O. (2003) Raising $\mathrm{Ca}^{2+}$ in L6 myotubes mimics effects of exercise on mitochondrial biogenesis in muscle. The FASEB Journal, 17, 675-681. doi:10.1096/fj.02-0951com

[32] Miura, S., Kawanaka, K., Kai, Y., Tamura, M., Goto, M., Shiuchi, T., Minokoshi, Y. and Ezaki, O. (2007) An increase in murine skeletal muscle peroxisome proliferator-activated receptor-gamma coactivator-1alpha (PGC1alpha) mRNA in response to exercise is mediated by beta-adrenergic receptor activation. Endocrinology, 148, 3441-3448. doi:10.1210/en.2006-1646

[33] Mathai, A.S., Bonen, A., Benton, C.R., Robinson, D.L. and Graham, T.E. (2008) Rapid exercise-induced changes in PGC-1alpha mRNA and protein in human skeletal muscle. Journal of Applied Physiology, 105, 1098-1105. doi:10.1152/japplphysiol.00847.2007

[34] Kiilerich, K., Gudmundsson, M., Birk, J.B, Lundby, C., Taudorf, S., Plomgaard, P., Saltin, B., Pedersen, P.A., 
Wojtaszewski, J.F. and Pilegaard, H. (2010) Low muscle glycogen and elevated plasma free fatty acid modify but do not prevent exercise-induced PDH activation in human skeletal muscle. Diabetes, 59, 26-32. doi:10.2337/db09-1032

[35] Wu, P., Inskeep, K., Bowker-Kinley, M.M., Popov, K.M. and Harris, R.A. (1999) Mechanism responsible for inactivation of skeletal muscle pyruvate dehydrogenase complex in starvation and diabetes. Diabetes, 48, 1593-1599. doi:10.2337/diabetes.48.8.1593

[36] Spriet, L.L., Tunstall, R.J., Watt, M.J., Mehan, K.A., Hargreaves, M. and Cameron-Smith, D. (2004) Pyruvate dehydrogenase activation and kinase expression in human skeletal muscle during fasting. Journal of Applied Physiology, 96, 2082-2087.

doi:10.1152/japplphysiol.01318.2003

[37] Cluberton, L.J., McGee, S.L., Murphy, R.M. and Hargreaves, M. (2005) Effect of carbohydrate ingestion on exercise-induced alterations in metabolic gene expression. Journal of Applied Physiology, 99, 1359-1363. doi:10.1152/japplphysiol.00197.2005

[38] Handschin, C. and Spiegelman, B.M. (2008) The role of exercise and PGClalpha in inflammation and chronic disease. Nature, 454, 463-469. doi:10.1038/nature07206 